\title{
Adolescent and Parent Content Preferences and Predictors of Intention to Use an Online Healthy Weight Website for Adolescents
}

\author{
Jacqueline Baulch (jacqueline.baulch@gmail.com) \\ RMIT University, GPO Box 2476V, Melbourne VIC 3001 Australia \\ Andrea Chester (andrea.chester@rmit.edu.au) \\ RMIT University, GPO Box 2476V, Melbourne VIC 3001 Australia \\ Leah Brennan (drleahbrennan@gmail.com) \\ Parenting Research Centre, East Melbourne 3002 \\ RMIT University, School of Medical Sciences, Bundoora VIC 3083 Australia
}

\begin{abstract}
This study evaluated adolescent and parent predictors of behavioural intention to use an online healthy weight website for adolescents using the Technology Acceptance Model (TAM), cohort (parent or adolescent), and adolescent BMI-for-age z-score. It also considered adolescent and parent preferences regarding the content of an online healthy weight website for adolescents. Participants included both a community and treatment sample of 67 adolescents and 76 parents who completed a questionnaire booklet containing demographic questions, the TAM scale and an evaluation of the value of possible website content. The hypothesis that TAM would be a significant predictor of behavioural intention to use the online weight management program was supported. Results contributed to an understanding of behavioural intention to use in the unique setting of an online healthy weight website and have important implications for researchers, clinicians and designers of obesity and online interventions.
\end{abstract}

Keywords: Online; internet, adolescent; obesity; overweight; Technology Acceptance Model.

\section{Introduction}

The widespread escalation in overweight and obesity requires increased attention and action in both developed and developing countries (World Health Organization [WHO], 2000). The prevalence of child and adolescent overweight and obesity has increased dramatically (Magarey, Daniels, \& Boulton, 2001). Currently it is estimated that $23 \%$ of Australian children and adolescents are above their healthiest weight (Commonwealth Scientific Industrial Research Organisation, 2008) and rates are expected to continue to rise (Haby \& Markwisk, 2008).

Concerns about the increase in obesity rates stem largely from its association with poor health and psychosocial outcomes. Overweight and obesity have been linked to long term health conditions including Type 2 diabetes, high blood pressure and cholesterol
(Goran, Ball, \& Cruz, 2003), an increased risk of developing certain types of cancer (World Cancer Research Fund and American Institute for Cancer Research, 2007) and decreased life expectancy (Olshansky et al., 2005). Overweight and obese children and adolescents, are at increased risk of becoming obese adults and developing associated health conditions (Guo, Wu, Chumlea, \& Roche, 2002; Magarey, Daniels, Boulton \& Cockington, 2003). Overweight and obesity have also been linked to adverse psychosocial outcomes, including lower self esteem (Strauss, 2000), being victims of bias, stereotyping and bullying by peers (Puhl \& Latner, 2007) and increased rates of body dissatisfaction and disordered eating (Wardle \& Cooke, 2005). Psychosocial outcomes are particularly pertinent for overweight and obese adolescents, given that this stage of life is typically associated with identity formation and self-evaluation (Allison \& Schultz, 2001).

A range of interventions have been used to reduce excess weight in children and adolescents including, diet and exercise programs, lifestyle interventions, pharmacotherapy and bariatric surgery (Luttikhuis et al., 2009). A recent Cochrane review concluded that combined behavioural, dietary and physical activity interventions produced significant and clinically meaningful reductions in overweight children and adolescents (Luttikhuis et al., 2009). Parental involvement, which typically involved parental education regarding healthy eating and activity and use of behavioural strategies, was highlighted as an important feature of treatment programs. This review also highlighted the lack of interventions targeting adolescents and the need to provide accessible, costeffective and sustainable interventions targeted to the needs of the individual. Internet-based intervention programs may go some way towards meeting this need.

Although in-person treatment modalities may be preferred (Harvey-Berino, Pintauro, \& Gold, 2002) the unprecedented prevalence rates for overweight and 
obesity, coupled with the expectation of continued increases, indicate that the expansion of prevention and treatment options is imperative; as is a reduction in costs associated with interventions. The internet is increasingly recognised as an efficacious and innovative alternative or adjunct to in-person treatment programs (Luce, Winzelberg, Zabinski, \& Osborne, 2003; Ritterband et al., 2003). Minimal therapist contact, in addition to the ability to disseminate individualised treatment programs (McCoy, Couch, Duncan, \& Lynch, 2005) potentially increase the economic feasibility of internet-delivered obesity treatment programs. The anonymity of the internet also makes it possible for overweight and obese individuals to seek treatment with reduced shame and embarrassment, factors commonly cited as barriers to treatment (Zabinski, Celio, Wilfley, \& Taylor, 2003). Furthermore, in contrast to more traditional face-to-face delivery methods, the internet enables access around the clock regardless of geographical location, thus removing the barriers of time constraints and isolation (Fontaine \& Allison, 2002; Ritterband et al., 2003).

Although online treatment programs have demonstrated efficacy across a range of contexts (for a review see Barak, Hen, Boniel-Nissim, \& Shapira, 2008), relatively few randomised controlled trials have assessed the suitability of this treatment modality for overweight and obesity (Authors, 2008). Although the area is one of increasing research interest, only a relatively small number of studies have explored online weight management for adults (e.g., Carter-Edwards, Bastian, Schultz, Ahinee, \& Østbye, 2009; HarveyBerino et al., 2002; Tate, Jackvony, \& Wing, 2003; Tate, Wing, \& Winett, 2001) and even fewer studies have evaluated online weight management programs for adolescents (e.g. Gow, Trace, \& Mazzeo, 2009; Wiliamson et.al., 2005).

Before investing resources in developing such programs, it has been suggested that researchers might benefit from the mindful adoption of this technology (Ritterband et al., 2003; Saber, Flores, Fagan, Kilmon, Williams, \& Ibitayo, 2005). While it is not possible to measure actual use prior to the development of an online program, an individual's intention to use can be measured. Intention to perform a particular behaviour has been found to predict eventual usage behaviour (Davis, 1989; Sheppard, Hartwick, \& Warshaw, 1988). Importantly, this finding has been replicated in a number of health settings, including blood donation (Bagozzi, 1981), weight loss (Schifter \& Ajzen, 1985), condom use (Albarracin, Johnson, Fishbein, \& Muellerleile, 2001) and AIDS prevention (Fisher, Fisher, \& Rye, 1995). Thus it has been argued that research focus on understanding individual determinants of intention to use online weight loss interventions before developing and implementing such programs.
A number of health behaviour and technology acceptance models have been developed to explain individual determinants of behavioural intention to use. The Technology Acceptance Model (TAM) (Davis, 1989) is considered one of the most influential and widely adopted of these models (Lee, Kozar, \& Larsen, 2003). The model posits two predictors of behavioural intention to use and subsequent usage behaviour: perceived usefulness (the degree to which a person believes that using a particular system would enhance his or her job performance and perceived ease of use (the degree to which a person believes that using a particular system would be free from effort) (Davis, 1989). The model explains between $33 \%$ to $70 \%$ of variance in intention to use, depending on the context of the study (Venkatesh, Morris, Davis, \& Davis, 2003). Of the two key variables proposed by TAM, perceived usefulness is consistently found to be the strongest determinant of behavioural intention to use (Adams, Nelson, \& Todd, 1992; Davis, 1989; Venkatesh et al., 2003).

Although parsimonious, the TAM has demonstrated robust characteristics across technologies, individual differences, cultures, settings and times (Davis, 1989; Mathieson, 1991; Straub, Keil, \& Brenner, 1997). In their meta-analysis, Ma and Liu (2004) estimated that in a three-year period alone, over 100 studies evaluated TAM. Researchers have demonstrated the empirical advantage of the model in relation to other theoretical perspectives (Davis, 1989; Mathieson, 1991), validated the original model through psychometric evaluations (Adams et al., 1992; Szajna, 1994), and tested the model across a number of cultures (Straub, Keil, \& Brenner, 1997) and across sex (Venkatesh \& Morris, 2000). Importantly, over 20 studies have tested the TAM in healthcare settings and according to Holden and Karsh (2010) it is "increasingly portrayed as a fitting theory for the healthcare context" (p.1).

Given that parental involvement has been identified as an important component of treatment programs for adolescent obesity (Luttikhuis et al., 2009), it is important to understand if there are differences in adolescent and parent behavioural intention to use. Research findings in this area are varied. For example, a higher proportion of younger people are online (Australian Bureau of Statistics, 2006), and general computer confidence is negatively correlated with age (Henderson, Deane, Barrekke, \& Mahar, 1995). However, individuals between the ages of 30-49 and 50-64 are more likely to use the internet for health information than those under 30 , and parents tend to search for health information for both themselves and their children (Pew, 2002). Thus, it is unclear whether parents or adolescents would have a more positive attitude towards an adolescent online weight management program.

Adolescent weight status may also influence intention to use a healthy weight website. While it appears that 
dietary restraint is more common in overweight individuals (Braet \& Wydhooge, 2000; Serdula et al., 1999; Wardle \& Johnson, 2002), restrictive behaviours are also apparent in those with normal to underweight BMI (Braet \& Wydhooge, 2000; Serdula et al., 1999). Further research is needed to determine whether BMI is a predictor of engagement in dietary related activities, such as an online weight management program.

The primary aim of the current study was to evaluate predictors of intention to use an online weight management program in combination with adolescent weight status. The study also aimed to explore possible differences between parent and adolescent behavioural intention to use. A related aim was to trial the use of the TAM framework as a tool in website planning. Before developing and implementing an online weight management program, researchers might also benefit from gathering information regarding potential users' preferences for program content. Thus, the final aim of this study was to provide information regarding parent and adolescent preferences for program content, as well as a brief evaluation of parent and adolescent internet usage behaviour.

\section{Method}

\section{Participants}

Participants included 67 adolescents $(M=15.90$ years, $S D=1.81$ years) and 76 parents of adolescents ( $M=46.25$ years, $S D=7.63$ years). Of the adolescents, 51 were female and 16 were male. Of the parents, 66 were female and 10 were male. Participants were recruited from two sources: a public, coeducation secondary school in South-West Victoria and past and present participants in the CHOOSE HEALTH adolescent obesity treatment program. CHOOSE HEALTH is a 10session cognitive behavioural program designed to improve eating and activity habits in overweight and obese adolescents with parental support (Brennan, Walkley, Fraser, Greenway, \& Wilks, 2008). Both parents and adolescents were recruited from each source, however as participants responded anonymously it is not possible to determine which participants were recruited from each source. Parents and adolescents were not matched.

\section{Materials}

Both the adolescent and parent questionnaires included demographic questions, a short description of the proposed weight management website, the TAM scale (Davis, 1989), research questions from Pew Foundation Internet and American Life Project (Pew, 2005) evaluating internet usage and experience and questions exploring possible website content. Demographic questions included age, gender, postcode, height, weight and two questions addressing feelings about height, weight and physical health. Parent's were also asked to report their child's height and weight so the influence of adolescent BMI on parent and adolescent intention to use an adolescent focused healthy weight website could be considered. Parents answered the remaining questions with reference to their own intention to use such a site.

The description of the website was as follows: "We are developing an online weight management program for young people and their parents. This is you! The website will include a program for developing and monitoring healthy weight goals, with ideas for rewards when your goals are achieved. Links to healthy eating and exercise ideas, together with charts for plotting your daily physical activity will also be included. The website will be colourful and interactive, with a discussion board for you to chat with other people. A health professional, such as a doctor, may also be available to answer any emails or queries you may have. When answering the questions in this booklet we would like you to keep the online weight management program we have described in mind. So we can make the website as interesting as possible, at the end of the questionnaire we will also be asking you to tell us what you think the online weight management program should include."

The TAM scale is a 12-item measure of perceived usefulness and perceived ease of use as determinants of behavioural intention to use technology (Davis, 1989). In the present study a modified version of the TAM was used, based on the items refined by Venkatesh et al. (2003). This modified version uses four items to measure perceived usefulness and four items to measure perceived ease of use. Behavioural intention to use was measured using three items extracted from the Unified Theory of Acceptance and Use of Technology (Venkatesh et al., 2003). Minor modifications were made to the 11 items used in the current study in order to accommodate adolescent reading and comprehension levels. As the original scale was designed for use in job settings, minor amendments were made for the specific research setting. For example, the question "I would find the system easy to use" was changed to "I would find the online weight management program easy to use". All 11 items used a 7-point Likert scale ranging from 1 = Strongly Disagree, to $7=$ Strongly Agree. Subscale scores are derived by adding the scores on all items in the subscale and dividing by the number of items in the subscale. All internal reliability consistencies for the modified TAM scale were greater than .70 (Venkatesh et al, 2003). The modified scale has also demonstrated sound psychometric properties in an online context (Martins \& Kellermann, 2004).

Research questions evaluating internet usage and experience were drawn from the PEW Foundation Internet and American Life Project (Pew, 2005). These questions were designed to explore internet access and online behaviour including confidence using the internet and experience with different forms of online 
information such as email, game playing, and blogs. Participants were asked whether they had ever looked for health or dieting information online. These questions used forced choice response formats such as "Yes, I have done this", "No, I have not done this" or "I don't know/remember if I have done this".

The final section of the questionnaire asked participants to choose from a checklist of possible features that they thought the online weight management program should include. This list was generated by psychologists with expertise in weight management and/or online interventions. Participants were asked to tick those items that they thought should be included. Proposed items included interaction and communication tools (chat room, discussion board, email feedback or phone support from a health professional), health behaviour education resources (food ideas, physical activity ideas, links to other helpful websites) and monitoring and planning tools (Body Mass Index [BMI] calculator, online journal, charts for recording physical activity and food consumption, timetables to help fit exercise into your day). Participants were asked to select as many features as they thought appropriate and were additionally invited to include any open-ended comments about features they thought the website should include.

\section{Procedure}

Ethics approval for the research was obtained from both RMIT University Human Research Ethics Committee and the Victorian Department of Education and Early Childhood Development. Information about the research project was made available to a public, coeducation secondary school in South-West Victoria and participants in an adolescent overweight and obesity treatment program. This approach was taken to ensure representation from both the general population and a treatment seeking sample as it was anticipated that a healthy weight website could be used by both populations. As participants responded anonymously it is not possible to determine which participants were recruited from each source. A plain language description of the study, consent form and questionnaire were available online and in paper copy. Participants under 18 years of age were required to gain parental consent prior to participating, with online consent modelling that of paper consent. Those participants who chose to complete the questionnaire on paper were provided with a reply paid envelope for confidential return. Of the 143 participants, the majority (63 adolescents and 60 parents) completed the questionnaire in paper format.

\section{Results}

Data was analysed using SPSS for Windows version 15.0. Table 1 presents descriptive statistics for all variables for parents and adolescents. The majority of adolescent and parent participants were female. The mean BMI-for-age z-score of adolescent participants, and the adolescent's of parent participants was in the healthy weight range. The mean TAM scores represent strong positive attitudes towards perceived usefulness and ease of use and moderately strong intention to use. All three means were higher than those reported by Venkatesh et al. (2003).

Table 1

Descriptive Statistics for Research Variables for Parents and Adolescents

\begin{tabular}{|c|c|c|c|c|c|}
\hline \multirow[b]{2}{*}{ Variable } & \multicolumn{3}{|c|}{$\begin{array}{l}\text { Parents } \\
n=76\end{array}$} & \multicolumn{2}{|c|}{$\begin{array}{c}\text { Adolescents } \\
n=67\end{array}$} \\
\hline & Range & $M$ & $S D$ & $M$ & $S D$ \\
\hline $\begin{array}{l}\text { Perceived } \\
\text { usefulness }\end{array}$ & $1-7^{a}$ & 5.18 & 1.16 & 5.04 & .98 \\
\hline $\begin{array}{l}\text { Perceived ease of } \\
\text { use }\end{array}$ & $1-7^{\mathrm{b}}$ & 5.28 & 1.20 & 5.48 & .97 \\
\hline $\begin{array}{l}\text { Body mass index } \\
\text { z-score }^{c}\end{array}$ & & .85 & 1.25 & .82 & 1.20 \\
\hline Age & & 46.25 & 7.63 & 15.90 & 1.81 \\
\hline Intention to use & $1-7^{\mathrm{d}}$ & 4.63 & 1.63 & 4.82 & 1.48 \\
\hline $\begin{array}{l}{ }^{\mathrm{a}} 1=\text { low perceive } \\
{ }^{\mathrm{b}} 1=\text { low perceiv } \\
\text { use; }{ }^{\mathrm{c} B o d y} \text { mass } \\
\text { body mass index; }\end{array}$ & $\begin{array}{l}\text { sefuln } \\
\text { ease }\end{array}$ & $\begin{array}{l}7=h \\
\text { se, } 7 \\
\text { cents i }\end{array}$ & h per & $\begin{array}{l}\text { ed use } \\
\text { ceived }\end{array}$ & $\begin{array}{l}\text { Iness; } \\
\text { ase of } \\
\text { scents } \\
\text { ention }\end{array}$ \\
\hline
\end{tabular}

Correlations were calculated for all variables. There was a significant positive correlation between behavioural intention to use and perceived usefulness $r$ $=.62, p<.01$ and perceived ease of use $r=.49, p<.01$. An independent samples t-test revealed no significant difference in behavioural intention to use between parents and adolescents $t(141)=-.76, p=.45$, thus both were included in a single regression analysis.

A stepwise multiple regression was conducted to explore the relative contribution of perceived usefulness, perceived ease of use, and BMI z-score to intention to use. Collinearity diagnostics revealed acceptable tolerance levels for each of the variables. Regression statistics are shown in Table 2. The model including perceived usefulness, perceived ease of use and BMI z-score explained $43.7 \%$ (43.9\% adjusted) of the variability in intention to use the online weight management program $F(3,139)=38.80, p<.001$. Perceived usefulness explained the largest amount of variance in intention to use accounting for $38.6 \%$ (38.2\% adjusted), while perceived ease of use and BMI accounted for $5.1 \%(4.7 \%$ adjusted) and $1.9 \%(1.5 \%$ adjusted) respectively. 
Table 2

Summary of Multiple Regression Analysis for Variables Predicting Behavioural Intention to Use

\begin{tabular}{lcccc}
\hline Variable & $S E B$ & $\beta$ & $t$ & $p$ \\
\hline $\begin{array}{l}\text { Perceived } \\
\quad \text { usefulness }\end{array}$ & .10 & .48 & 6.65 & $\geq .01$ \\
$\begin{array}{l}\text { Perceived ease } \\
\quad \text { of use }\end{array}$ & .10 & .24 & 3.42 & $\geq .01$ \\
BMI & .08 & .14 & 2.19 & $>.03$ \\
\hline
\end{tabular}

Note. $\mathrm{BMI}=$ body mass index.

Percentage frequencies were calculated to establish a profile of parent and adolescent behaviour online and are reported in Table 3. Overall a similar profile of online behaviour emerged for both parents and adolescents. The overwhelming majority of participants from both groups had access to the internet and had done so for at least three years. Slightly more parents than adolescents were online at least once per week, while adolescents reported higher rates of confidence when using the internet. Approximately one-third of parents reported visiting a weight loss website, with under one-quarter of adolescents doing the same.

Table 3

Parent and Adolescent Online Behaviour Profile

\begin{tabular}{lcc}
\hline & \multicolumn{2}{c}{ Percentage frequency } \\
\cline { 2 - 3 } & Adolescents & Parents \\
\hline Access to the internet & 96 & 88 \\
Have had access for 3 & 85 & 82 \\
years or more & & \\
Internet access at home & 93 & 84 \\
Broadband connection at & 84 & 88 \\
home & & \\
Accessing internet at & 75 & 82 \\
least once per week & & 76 \\
At least moderately & 88 & \\
confident when using & & 35 \\
the internet & & \\
Visited a weight loss & 22 & \\
website & & \\
\hline
\end{tabular}

Parents and adolescents were asked to indicate which of the listed features should be included in a healthy weight website. Percentage frequencies were calculated and a summary is provided in Table 4. Again a similar pattern of results emerged for both parents and adolescents. However, it should be noted that overall, adolescents endorsed more of the features proposed. Food ideas, a BMI calculator and physical activity ideas were the three most popular features for parents and adolescents. Computer-mediated communication features, including a chat room and online journal were the least popular features for the two groups with less than half the adolescents and less than one-third of parents indicating approval.
Table 4

Features Parents and Adolescents Think the Website Should Include

\begin{tabular}{lcc}
\hline & \multicolumn{2}{c}{ Percentage frequency } \\
\cline { 2 - 3 } Feature & Adolescents & Parents \\
\hline Food ideas & 97 & 88 \\
BMI calculator & 96 & 78 \\
Physical activity ideas & 96 & 76 \\
Timetables & 88 & 62 \\
Charts - food & 84 & 68 \\
Email feedback & 82 & 74 \\
Charts - physical activity & 79 & 72 \\
Login & 79 & 66 \\
Links to other websites & 76 & 72 \\
Phone support & 61 & 55 \\
Discussion board & 57 & 38 \\
Chat room & 52 & 33 \\
Online journal & 37 & 36 \\
\hline
\end{tabular}

Note. $\mathrm{BMI}=$ body mass index.

In terms of therapist contact as a feature of the website, more parents and adolescents endorsed email feedback than phone support. Several themes were identified in response to participant's open-ended comments about possible website features. Namely, both parents and adolescents suggested that making the website fun and interactive would increase usage. Sample responses suggested this could be achieved by "including games about food groups and physical activity ideas", "ideas for goals and rewards" and "including charts for food and exercise". Furthermore, a positive, encouraging focus was identified as an important element of the website for both groups. Sample responses suggested that this could be achieved through "motivation and success stories" "positive feedback" and "daily motivation quotes".

\section{Discussion}

The current study evaluated predictors of intention to use an online weight management program using the framework of the TAM model. The results of this study are consistent with previous research, which suggests that both perceived usefulness and perceived ease of use are key determinants of intention to use information technology (Adams et al., 1992; Davis, 1989; Mathieson, 1991). No significant differences in behavioural intention to use arose between parents and adolescents. Findings of the present study contribute to the growing body of evidence indicating the primary role of perceived usefulness in predicting intention to use (Adams et al., 1992; Davis, 1989; Venkatesh et al., 2003). Additionally, this study extended the original TAM model to examine acceptance and intention to use information technology to the field of health, specifically overweight and obesity. 
Beyond its theoretical contribution, the TAM provides information with practical application in the planning, design and implementation of future online interventions generally and online weight management programs specifically. In particular the findings of the current study have important implications for researchers and website designers. It is apparent that users are prepared to cope with a certain degree of difficulty when using a website that provides them with an essential or useful function, such as assisting with weight management. However, no amount of ease of use can compensate for a website that is not seen to serve a useful function. Finding the right balance between perceived usefulness and perceived ease of use will be a challenge for future researchers in this field.

The TAM scale may provide a simple, effective and low-cost method for obtaining user feedback on different system features or design approaches during the various stages of website planning. Following the implementation of online programs, the scale may be useful in assisting with the diagnosis of problems relating to user acceptance and subsequent usage behaviour (Adams et al., 1992). Furthermore, within a clinical setting the TAM scale has potential as a costeffective screening tool differentiating between individuals who are likely to benefit from online programs and those for whom face-to-face treatment modalities are more suitable. Making this differentiation prior to a participant's involvement may be particularly important, as it recognises that online interventions are not of universal appeal (HarveyBerino et al., 2002) and may help to decrease attrition.

Although there was no significant difference in behavioural intention to use between parents and adolescents, this finding contributed to a more detailed understanding of behavioural intention to use an online weight management program. Findings suggest that parents were as likely as adolescents to indicate their intention to use the online weight management program. This finding was consistent with the profile of parent and adolescent online behaviour discussed previously, with a similar pattern emerging for both groups. Results from the current study indicate that despite higher internet access rates amongst adolescent participants, parents are online more frequently than adolescents and over three-quarters are moderately confident when using the internet. It is plausible that the gap in online access and experience between younger and older people is demonstrating signs of fading. In the United States this appears to be the case (Pew, 2007) and it is possible that the Australian population is emulating this pattern.

Useful descriptive findings emerged for parent and adolescent's preferences for program content. Interactivity was considered an essential feature of the proposed program. This finding is reflected in literature describing online program development, suggesting that interactivity increases engagement and motivation to use and complete a treatment program (Ritterband et al., 2003).

When interpreting the findings from the current research, several limitations need to be recognised. First, although behavioural intention to use the online weight management program was measured, the relationship between intention and use behaviour was not. At present the online weight management program does not exist, so measuring usage behaviour was impossible. Although there is substantial empirical support for the intention-behaviour link for general technology behaviours (Davis, 1989; Sheppard et al., 1988) and health behaviours specifically (Albarracin et al., 2001; Bagozzi, 1981; Fisher et al., 1995; Schifter \& Ajzen, 1985) it should be acknowledged that behavioural intention to use is not a perfect predictor of usage behaviour.

The combination of participants recruited from two distinct samples is an additional limitation of the current study. Students from a rural high school, and participants in a weight loss intervention were invited to participate in the current study. As responses were anonymous it was not possible to determine the source of participants or identify potentially important differences between these groups. Similarly, to maximise participation individual adolescents and parents were permitted to participate thus data was not paired. Thus it was not possible to consider parentadolescent pairs. These limitations should be addressed in future studies so differences in community and treatment participants; and relationships between parent-adolescent pairs can be considered.

Finally, given that the participants were self-selecting and predominantly female, it is unlikely that the current sample is representative of the general population. However, it may be that respondents were representative of individuals the online program will be targeting, that is, individuals who are seeking online weight loss or weight management strategies and/or who are comfortable with the online medium. Furthermore, the gender imbalance apparent in the current study is consistent with previous research in online psychology and health (Lorig, Ritter, Laurent \& Plant, 2006) as well as weight loss (Harvey-Berino et al., 2002; Tate et al., 2003; Weinstein, 2006) Future research may focus on examining the lack of male motivation in online psychology and weight loss research.

Moving forward, researchers and clinicians should continue developing online weight loss interventions and evaluate their efficacy through a range of approaches including randomised controlled trials. Measuring attitudes towards such interventions will be an important step in the design, development and implementation of these programs. In particular the TAM scale may provide a method of identifying those individuals with an increased motivation to use online programs. Targeting interventions towards these 
individuals may lead to enhanced treatment retention and better outcomes.

The prevalence rate for obesity has increased dramatically worldwide in both adults and children (WHO, 2000). A number of face-to-face weight loss treatments have been identified as efficacious, however their ability to reach the substantial number of individuals requiring treatment is limited (Luttikhuis, 2008). Given the considerable number of people who now access the internet daily (Pew, 2005), online weight loss programs may provide a solution to this dilemma. However, before investing time and resources in the development and implementation of such programs there is a need for research which identifies individual determinants of user acceptance and intention to use (Saber et al., 2005). The TAM model has provided a parsimonious and effective method for predicting individual determinants of user acceptance and intention to use an online weight management program. The inclusion of two cohorts (parent and adolescents) as a variable for analysis also contributed to an understanding of individuals most likely to adopt an online weight loss program. The current paper therefore adds to the increasing literature in this area, providing a framework to inform the development of online interventions in the area of obesity and overweight for adolescents and their parents.

\section{References}

Adams, D. A., Nelson, R. R., \& Todd, P. A. (1992). Perceived usefulness, ease of use, and usage of information technology: A replication. MIS Quarterly, 16, 227-247.

Albarracin, D., Johnson, B. T., Fishbein, M., \& Muellerleile, P. A. (2001). Theories of reasoned action and planned behaviour as models of condom use: A meta-analysis. Psychological Bulletin, 127, 142-161.

Allison, B. N., \& Schultz, J. B. (2001). Interpersonal identity formation during early adolescence. Adolescence, 36, 509-524.

Australian Bureau of Statistics (2006). Household use of information technology (8146). Canberra: ABS.

Bagozzi, R. P. (1981). Attitudes, intentions, \& behaviour: A test of some key hypotheses. Journal of Personality and Social Psychology, 41, 606-627.

Barak, A., Hen, L., Boniel-Nissim, M., \& Shapira, N. (2008). A comprehensive review and a meta-analysis of the effectiveness of internet-based psychotherapeutic interventions. Journal of Technology in Human Services, 26, 109-160.

Baulch, J., Chester, A., \& Brennan, L. (2008). Treatment alternatives for overweight and obesity: The role of online interventions. Behaviour Change, 25, 1-14.

Braet, C., \& Wydhooge, K. (2000). Dietary restraint in normal weight and overweight children: A cross- sectional study. International Journal of Obesity, 24, 314-318.

Brennan L, Walkley, J, Fraser, S, Greenway, K. \& Wilks R, (2008). Motivational interviewing and cognitive behaviour therapy in the treatment of adolescent overweight and obesity: Study design and methodology. Contemporary Clinical Trials, 29, 359. 375 .

Carter-Edwards, L., Bastian, L.A., Schultz, M., Ahinee, A., \& Østbye, T. (2009). An internet-based weight loss intervention initiated by a newspaper. Preventing Chronic Disease, 6 (3), A101.

Commonwealth Scientific Industrial Research Organisation (2008), 2007 Australian National Children's Nutrition and Physical Activity Survey. Australian Government: Canberra.

Davis, F. D. (1989). Perceived usefulness, perceived ease of use, and user acceptance of information technology. MIS Quarterly, 13, 319-340.

Fisher, W. A., Fisher, J. D., \& Rye, B. J. (1995). Understanding and promoting aids-preventative behaviour: Insights from the theory of reasoned action. Health Psychology, 14, 255-264.

Fontaine, K. R., \& Allison, D. B. (2002). Obesity and the internet. In C. D. Fairburn \& K. D. Brownell (Eds.), Eating disorders and obesity: A comprehensive handbook (2nd ed.) (pp. 609-612). New York: The Guilford Press.

Goran, M.I., Ball, G.D.C., \& Cruz, M.L. (2003). Obesity and risk of type 2 diabetes and cardiovascular disease in children and adolescents. Journal of Clinical Endocrinology and Metabolism. 88(4), 14171427.

Gow, R.W., Trace, S.E., \& Mazzeo, S.E. (2009). Preventing weight gain in first year college students: An online intervention to prevent "freshman fifteen. Eating Behaviors, 11 (1), 33-39.

Guo, S.S., Wu, W., Chumlea, W. C., \& Roche, A. F. (2002). Predicting overweight and obesity in adulthood from body mass index values in childhood and adolescence. American Journal Clinical Nutrition, 76(3), 653-658.

Haby, M., \& Markwick, A. (2008). A future prevalence of overweight and obesity in Australian children and adolescents, 2005-2025. Department of Human Services: Melbourne.

Harvey-Berino, J., Pintauro, S. J., \& Gold, E. C. (2002). The feasability of using internet support for the maintenance of weight loss. Behavior Modification, 26, 103-116.

Henderson, R., Deane, F., Barrelle, K., \& Mahar, D. (1995). Computer anxiety: Correlates, norms and problem definition in health care and banking employees using the Computer Attitude Scale. Interacting with Computers, 7, 181-193.

Holden, R. J., \& Karsh, B. (2010). The technology acceptance model: Its past and its future in health care. Journal of Biomedical Informatics, 43, 159-172. 
Lee, Y., Kozar, K. A., \& Larsen, K. R. T. (2003). The technology acceptance model: Past, present, and future. Communications of the Association for Information Systems, 12, 752-780.

Lorig, K. R., Ritter, P. L., Laurent, D. D., \& Plant, K. (2006). Internet-based chronic disease selfmanagement: A randomized trial. Medical Care, 44, 964-971.

Luce, K. H., Winzelberg, A. J., Zabinski, M. F., \& Osborne, M. I. (2003). Internet-delivered psychological interventions for body image dissatisfaction and disordered eating. Psychotherapy: Theory, Research, Practice, Training, 40, 148-154.

Luttikhuis, H. O., Baur, L., Jansen, H., Shrewsbury, V. A., O’Malley, C., Stolk, R. P. \& Summerbell, C. D. (2009). Interventions for treating obesity in children. Cochrane Database of Systematic Reviews. Issue 1. Art. No.: CD001872. DOI: 10.1002/14651858.CD001872.pub2.

Ma, Q., \& Liu, L. (2004). The technology acceptance model: A meta-analysis of empirical findings. Journal of Organizational and End User Computing, 16, 5972 .

Magarey, A.M., Daniels, L.A., \& Boulton, T.C. (2001) Prevalence of overweight and obesity in Australian children and adolescents: reassessment of 1985 and 1995 data against new standard international definitions. Medical Journal of Australia, 174, 561564

Magarey, A.M., Daniels, L. A., Boulton, T. J. \& Cockington, R. A.,(2003). Predicting obesity in early adulthood from childhood and parental obesity. International Journal of Obesity. 27, 505-513.

Martins, L. L., \& Kellermann, F. W. (2004). A model of business school students' acceptance of a webbased course management system. Academy of Management Learning Education, 3, 7-26.

Mathieson, K. (1991). Predicting user intentions: Comparing the technology acceptance model with the theory of planned behaviour. Information Systems Research, 2, 173-191.

McCoy, M. R., Couch, D., Duncan, M. D., \& Lynch, G. S. (2005). Evaluating an internet weight loss program for diabetes prevention. Health Promotion International, 20, 221-228.

Olshansky, S.J., Passoro, D. J., Hershow, R.C., Layden, J., Carnes, B. A., Brody, J. Hayflick, L., Butler, R. N., Allison, D. B., \& Ludwig, D. S. (2005). A potential decline in life expectancy in the United States in the 21st century. New England Journal of Medicine. 352(11), 1138-1146.

Pew (2002). Parents online. Washington DC: Pew Internet and American Life Project.

Puhl, R. M., \& Latner, J. D. (2007). Stigma, obesity and the health of the nation's children. Psychological Bulletin, 133, 557-580.

Ritterband, L. M., Gonder-Frederick, L. A., Cox, D. J., Clifton, A. D., West, R. W., \& Borowitz, S. M.
(2003). Internet interventions: In review, in use, and into the future. Professional Psychology: Research and Practice, 34, 527-534.

Saber, J., Flores, I., Fagan, M. H., Kilmon, C., Williams, J., \& Ibitayo, K. (2005). If you build it, will they come? Challenges in e-learning delivery system choice. Issues in Information Systems, 6, 197-203.

Schifter, D. E., \& Ajzen, I. (1985). Intention, perceived control, and weight loss: An application of the theory of planned behaviour. Journal of Personality and Social Psychology, 49, 843-851.

Serdula, M. K., Mokdad, A. H., Williamson, D. F., Galuska, D. A., Mendlein, J. M., \& Heath, G. W. (1999). Prevalence of attempting weight loss and strategies for controlling weight. JAMA, 282, 13531358.

Sheppard, B. H., Hartwick, J., \& Warshaw, P. R. (1988). A theory or reasoned action: A meta-analysis of past research with recommendations for modifications and future research. Journal of Consumer Research, 15, 325-343.

Straub, D., Keil, M, \& Brenner, W. (1997). Testing the technology acceptance model across cultures: A three country study. Information and Management, 33, 111.

Strauss, R. S. (2000). Childhood obesity and selfesteem. Pediatrics, 105, 15-20.

Szajna, B. (1994). Software evaluation and choice: Predictive validation of the technology acceptance instrument. MIS Quarterly, 18, 319-324.

Tate, D. F., Jackvony, E. H., \& Wing, R. R. (2003). Effects of internet behavioral counseling on weight loss in adults at risk for type 2 diabetes: A randomized trial. JAMA, 289, 1833-1836.

Tate, D. F., Wing, R. R., \& Winett, R. A. (2001). Using internet technology to deliver a behavioural weight loss program. Journal of the American Medical Association, 285, 1172-1177.

Venkatesh, V., \& Morris, M. G. (2000). Why don't men ever stop to ask for directions? Gender, social influence, and their role in technology acceptance and usage behaviour. MIS Quarterly, 24, 115-139.

Venkatesh, V., Morris, M. G., Davis, G. B., \& Davis, F. D. (2003). User acceptance of information technology: Toward a unified view. MIS Quarterly, 27, 425-478.

Wardle, J. \& Cooke, L. (2005). The impact of obesity on psychological well-being. Best Practice and Research Clinical Endocrinology and Metabolism, 19, 421-440.

Wardle, J., \& Johnson, F. (2002). Weight and dieting: examining levels of weight concern in British adults. International Journal of Obesity, 26, 1144-1149.

Weinstein, P. K. (2006). A review of weight loss programs delivered via the internet. The Journal of Cardiovascular Nursing, 21, 251-258.

World Cancer Research Fund and American Institute for Cancer Research. (2007). Food, Nutrition, 
Physical Activity, and the Prevention of Cancer: A Global Perspective. American Institute for Cancer Research: Washington DC.

World Health Organization. (2000). Obesity: Preventing and managing the global epidemic. Geneva: WHO.

Zabinski, M. F., Celio, A. A., Wilfley, D. E., \& Taylor, C. B. (2003). Prevention of eating disorders and obesity via the internet. Cognitive Behaviour Therapy, $32,137-150$.

Correspondence to: Jacqueline Baulch RMIT University, GPO Box 2476V, Melbourne 3001 Australia

Email: jacqueline.baulch@gmail.com

\section{Research Profile}

Jacqueline Baulch completed this research while undertaking her Bachelor of Applied Science (Honours) (Psychology) at RMIT University, Melbourne. She is currently completing her Doctor of Psychology (Clinical Psychology) at Swinburne University. Her research thesis has involved the development and evaluation of an online therapist-assisted treatment program for bulimia nervosa. Her research interests include eating disorders, overweight and obesity, online treatment programs and rural mental health.

Andrea Chester is an Associate Professor in the School of Health Sciences at RMIT University. Her research interests include the evaluation of online interventions for the treatment of mental health and the use of online interventions for the treatment of mental health and the use of online technologies for learning and teaching. Her online intervention research has included collaborations to treat shyness and bipolar disorder, reduce harmful drinking amongst university students, and decrease stigma associated with mental illness in the workplace.

Dr Leah Brennan is a clinical, health and developmental psychologist and a Lecturer in the Doctor of Clinical Psychology Program at Monash University School of Psychology and Psychiatry. Her research interests involve the application of psychological approaches to understand, prevent and treat obesity and disordered eating (including eating disorders) in children, adolescents and adults. The role of parents in the promotion of healthy lifestyles in children is also a strong research interest. Leah also has experience in a range of clinical settings including community based family intervention services, and hospital based clinics for the treatment of obesity and eating disorders. This clinical experience has strengthened her belief in the importance of developing, evaluating, and disseminating evidence-based interventions for use in real world settings. 